\title{
Analisis Risiko Rantai Pasok Beton Ready Mix pada Proyek Hotel Batiqa Surabaya
}

\author{
Arvin Irshad Prabowo dan Cahyono Bintang Nurcahyo \\ Jurusan Teknik Sipil, Fakultas Teknik Sipil dan Perencanaan Institut Teknologi Sepuluh Nopember (ITS) \\ J1. Arief Rahman Hakim, Surabaya 6011 \\ e-mail: bintang@ce.its.ac.id
}

\begin{abstract}
Abstrak-Dalam upaya memenuhi ekspektasi dari pemilik proyek Hotel Batiqa, Kontraktor tentu harus meningkatkan kinerja dari perusahaan untuk menghasilkan produk bermutu tinggi, tepat waktu, dan efisien. Maka dari itu, pada umumnya para kontraktor menerapkan manajemen rantai pasok dalam pelaksanaan proyek dari awal sampai akhir. Dalam pelaksanaannya, manajemen rantai pasok mempunyai risiko negatif. Risiko tersebut harus dianalisis sebelumnya, karena risiko tersebut dapat mengakibatkan kerugian bagi kontraktor. Manajemen risiko diawali dengan melakukan identifikasi risiko yang dibagi menjadi tiga aliran, yaitu aliran material/fisik, aliran finansial, dan aliran informasi, dengan melakukan survei pendahuluan kepada pelaku proyek dalam rantai pasok beton ready mix untuk mendapatkan variabel risiko yang relevan di lapangan, lalu setelah itu melakukan survei utama untuk mendapatkan nilai persepsi dari probabilitas dan dampak dari variabel risiko. Dari hasil survei tersebut akan dianalisis dengan matriks probabilitas dan dampak untuk mengkategorikan tingkatan variabel risiko. Berikutnya adalah untuk mengetahui respon risiko terhadap variable berkategori tinggi tersebut.
\end{abstract}

Dari hasil analisis data diketahui bahwa apabila risiko berkategori tinggi dari persepsi kontraktor terhadap pemasok beton ready mix terjadi masing-masing satu variabel di aliran finansial dan informasi. Beda halnya untuk persepsi pemasok ready mix terhadap kontraktor, risiko berkategori tinggi terjadi hanya satu variabel pada aliran finansial. Semua pihak yang terlibat dalam aktivitas rantai pasok proyek memilih opsi respon risiko dengan mengurangi dampak risiko apabila risiko tersebut terjadi di lapangan.

Kata Kunci_-Analisis Risiko, Hotel, Rantai Pasok.

\section{PENDAHULUAN}

\section{A. Latar Belakang}

$\mathrm{P}$ ELUANG pasar bisnis perhotelan di kota besar di Indonesia, khususnya Surabaya, diperkirakan tidak akan habis karena terus meningkatnya kesibukan dari aktivitas bisnis. Sebagai salah satu perusahaan yang bergerak di bidang properti dan perhotelan di Indonesia, PT. Hotel Batiqa Management Tbk. menjadi salah satu perusahaan yang tertarik untuk melakukan investasi dengan membangun hotel di kawasan Surabaya

Dalam mewujudkan visi dan misi PT. Hotel Batiqa Management Tbk. untuk menjadikan Hotel Batiqa menjadi hotel yang paling dipercaya dan disegani di Asia Tenggara, PT. Hotel Batiqa Management Tbk. menjalin kerjasama dengan PT. Nusa Raya Cipta Tbk sebagai General Contractor dari proyek
Hotel Batiqa Surabaya. Sebagai salah satu penyedia jasa kontruksi swasta besar di Indonesia, memenuhi ekpestasi dan kepuasan pelanggan tentu menjadi prioritas utama dari PT. NRC. Salah satu usaha ini adalah meningkatkan kinerja tim dengan cara menghasilkan produk yang bermutu tinggi dengan harga yang kompetitif. Melakukan efisiensi dan efektifitas kinerja dengan strategi manajemen rantai pasok adalah salah satu metode yang umunya dilakukan.

Manajemen rantai pasok secara kosep adalah usaha meningkatkan produktivitas perusahaan dalam rantai suplai melalui aliran kuantitas bahan, efisiensi waktu dan biaya, serta lokasi[1]. Akan tetapi, setiap kegiatan termasuk juga penerapan manajemen rantai pasok juga mempunyai risiko, begitu juga dengan rantai suplai dari beton ready mix. Risiko adalah probabilitas suatu hasil yang berbeda dengan yang diharapkan, yang dimaksud dari hasil yang berbeda adalah hasil negatif atau kerugian[2]. Pada pelaksanaan dalam proyek, sering kali kesalahan komunikasi dan kesalahan teknis setiap alur dari proses rantai suplai beton ready mix dari hulu ke hilir menjadi hal yang sangat umum di lapangan yang dapat mengakibatkan kerugian pada pihak-pihak yang terkait pada rantai suplai beton ready mix. Sehingga dalam usaha melakukan manajemen rantai pasok, risiko harus dikelola dengan baik agar outputnya tidak merugikan perusahaan kontraktor dan juga pelanggan.

Oleh karena itu, mengidentifikasi dan mengevaluasi risiko untuk mengurangi kejadian yang merugikan menjadi hal yang wajib untuk dilakukan oleh seluruh perusahaan, tidak terkecuali perusahaan konstruksi. Dengan manajemen risiko, perusahaan yang berkaitan mampu memberi arahan dalam melihat risiko yang timbul baik secara jangka pendek dan jangka panjang sehingga dapat mengambil keputusan dengan menimalisir kemungkinan kerugian terhadap perusahaan. Bila manajemen risiko diterapkan pada strategi manajemen rantai pasok, maka perusahaan kontraktor dapat mengurangi kemungkinan terjadinya risiko dalam aktivitas penghantaran bahan material dari pemasok ke pelanggan. Sehingga produk yang dihasilkan diharapkan lebih murah, tepat waktu, dan berkualitas.

\section{B. Tujuan}

Tujuan yang hendak dicapai dalam penulisan penelitian ini adalah :

1. Mengetahui risiko kategori tinggi dalam aktivitas rantai pasok beton ready mix pada proyek Hotel Batiqa Surabaya.

2. Mengetahui upaya penanganan risiko kategori tinggi dalam aktivitas rantai pasok beton ready mix pada proyek Hotel Batiqa Surabaya 


\section{Batasan Masalah}

Berikut adalah lingkup pembahasan dan batasan masalah dalam penulisan penelitian :

1. Responden penelitian adalah para pelaku proyek Hotel Batiqa Surabaya.

2. Risiko yang diteliti adalah risiko dari sudut pandang kontraktor dan pemasok

3. Risiko yang diteliti adalah risiko dalam aktivitas rantai pasok pada hubungan kerja dua arah antara kontraktor dengan pemasok.

4. Variabel risiko dalam aktivitas rantai pasok yang ditinjau pada penelitian ini yaitu variabel aliran material, aliran finansial, dan aliran informasi.

5. Jenis suplai material yang diteliti hanya material utama pada struktur bangunan atas yaitu beton ready mix.

\section{METODOLOGI}

\section{A. Diagram Alur Penelitian}

Alur penelitian yang dalam analisis risiko rantai pasok dapat dilihat pada Gambar 1 :

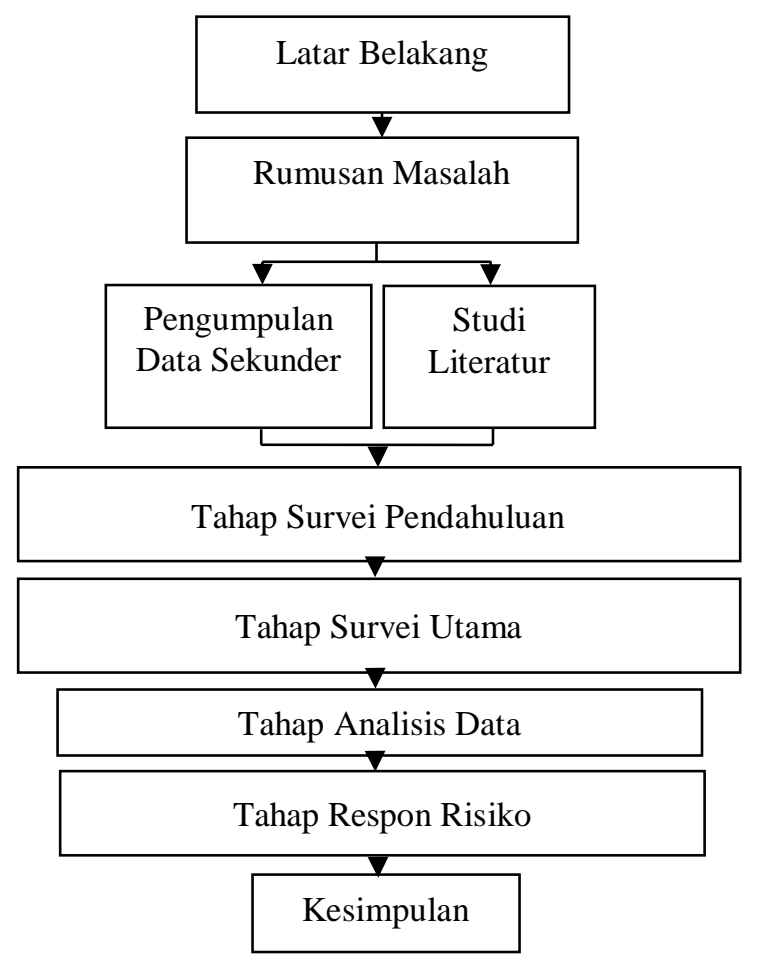

Gambar 1. Diagram Alur Penelitian

\section{B. Data Penelitian}

Data penelitian yang dibutuhkan pada proyek Hotel Batiqa dapat dilihat pada Tabel 1 :

Tabel 1

Data Primer dan Data Sekunder

\begin{tabular}{|c|c|}
\hline Data Primer & Data Sekunder \\
\hline \begin{tabular}{lrr}
\multicolumn{3}{l}{ Data dari survei kuisioner dan } \\
wawancara dari pihak \\
kontraktor (PT. Nusa & Raya \\
Cipta) & &
\end{tabular} & $\begin{array}{l}\text { Data identitas proyek yang } \\
\text { sedang berjalan }\end{array}$ \\
\hline
\end{tabular}

Data dari survei kuisioner dan wawancara dari pihak supplier Data identitas responden (PT. Holcim Beton)

Data perusahaan kontraktor dan supplier

\section{Penerapan Rantai Pasok}

Penerapan rantai pasok pada proyek Hotel Batiqa dapat dilihat pada Gambar 2 :

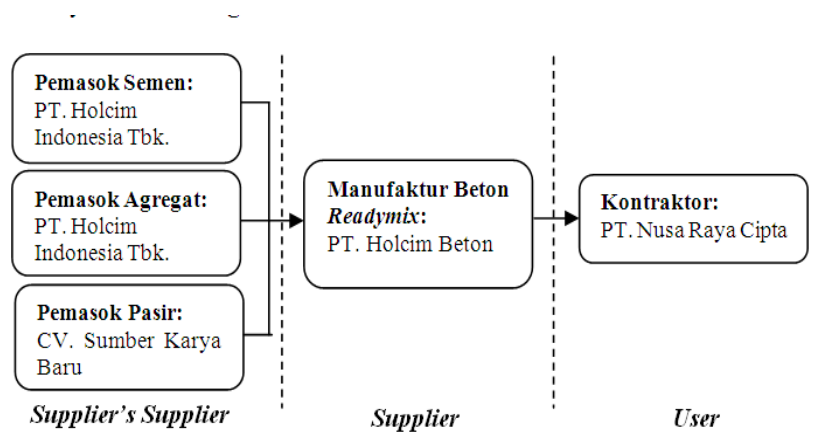

Gambar 2. Rantai Pasok Beton Ready Mix pada Proyek Hotel Batiqa

\section{Variabel Penilitian}

Penelitian ini dilakukan untuk mengidentifikasi risiko apa saja yang terjadi pada aktivitas rantai pasok dalam perspektif yang berbeda dari tiap pelaku, yaitu :

- Perspektif PT. NRC sebagai kontraktor terhadap PT. Holcim Beton sebagai pemasok ready mix

- Perspektif PT. Holcim Beton sebagai pemasok ready mix terhadap PT. NRC sebagai kontraktor.

Variabel risiko didapat dari studi literatur [2], [3], [4], [5], [6], [7]. Variabel risiko dibagi dalam tiga kategori, yaitu aliran informasi, aliran material atau fisik, dan aliran finansial seperti yang disajikan di Tabel 2 :

Tabel 2

Variabel Risiko Rantai Pasok pada Hubungan Kerja Kontraktor terhadap Pemasok Beton Ready Mix

\begin{tabular}{|c|c|}
\hline No & $\begin{array}{l}\text { Aliran Material/Fisik } \\
\text { Variabel Risiko }\end{array}$ \\
\hline $\mathrm{A} 1$ & $\begin{array}{l}\text { Ketidakstabilan suplai material oleh pemasok ready mix kepada } \\
\text { pihak kontraktor }\end{array}$ \\
\hline $\mathrm{A} 2$ & $\begin{array}{l}\text { Risiko keterlambatan pengiriman oleh pemasok ready mix kepada } \\
\text { pihak kontraktor yang diakibatkan oleh proses mendapatkan } \\
\text { materialn pengganti }\end{array}$ \\
\hline A3 & $\begin{array}{l}\text { Kerusakan material saat pengiriman material oleh pemasok } \\
\text { kepada pihak kontraktor }\end{array}$ \\
\hline A4 & $\begin{array}{l}\text { Ketidaksesuaian antara volume material yang dikirim oleh } \\
\text { pemasok ready mix kepada pihak kontraktor dengan volume } \\
\text { permintaan dari pihak kontraktor }\end{array}$ \\
\hline A5 & $\begin{array}{l}\text { Ketidaksesuaian mutu/kualitas material yang dikirim oleh } \\
\text { pemasok ready mix kepada pihak kontraktor terhadap standar } \\
\text { mutu sesuai spesifikasi pada kontrak }\end{array}$ \\
\hline A6 & $\begin{array}{l}\text { Kegagalan pengiriman material yang dikirim oleh pemasok ready } \\
\text { mix kepada pihak kontraktor karena lokasi proyek yang kurang } \\
\text { jelas atau sulit dilalui }\end{array}$ \\
\hline A7 & Perizinan pengadaan material khusus yang berbelit \\
\hline A8 & Pembatasan impor material dan peralatan \\
\hline A9 & $\begin{array}{l}\text { Risiko akibat persyaratan ke yang berlaku di sekitar lingkungan } \\
\text { proyek terkait pengadaan material oleh pemasok ready mix } \\
\text { kepada kontraktor di lokasi proyek }\end{array}$ \\
\hline No & $\begin{array}{l}\text { Aliran Finansial } \\
\text { Variabel Risiko }\end{array}$ \\
\hline B1 & $\begin{array}{l}\text { Pembayaran yang terlambat atau bahkan tidak terbayarnya } \\
\text { pemasok ready mix karena keuangan kontraktor yang bermasalah }\end{array}$ \\
\hline
\end{tabular}




\begin{tabular}{cl} 
B2 & $\begin{array}{l}\text { Harga yang diberikan oleh pemasok ready mix kepada pihak } \\
\text { kontraktor kurang kompetitif }\end{array}$ \\
B3 & Kesalahan dalam estimasi biaya \\
B41 & $\begin{array}{l}\text { Frekuensi pembayaran yang dilakukan oleh pihak kontraktor } \\
\text { kepada pemasok ready mix }\end{array}$ \\
B5 & Risiko akibat fluktuasi kurs mata uang \\
B6 & Risiko akibat eskalasi kenaikan harga material \\
B7 & Terjadi peningkatan tarif pajak barang atau jasa \\
B8 & Terjadinya krisis ekonomi \\
\hline No & \multicolumn{1}{c}{ Aliran Informasi } \\
& \multicolumn{1}{c}{ Variabel Risiko } \\
\hline C1 & Ketidakjelasan pemasok ready mix dalam memberikan informasi \\
C2 & Minimnya kepercayaan kontraktor terhadap pemasok ready mix \\
C3 & $\begin{array}{l}\text { Minimnya sumber daya alat dan/atau manusia yang dimiliki } \\
\text { perusahaan pada proses pertukaran informasi }\end{array}$ \\
C4 & $\begin{array}{l}\text { Perubahan spesifikasi dari material yang telah dipesan oleh } \\
\text { kontraktor kepada pihak pemasok ready mix }\end{array}$ \\
C5 & $\begin{array}{l}\text { Pengajuan klaim dari pihak kontraktor atas ketidakpuasan } \\
\text { material yang telah dikirim oleh pemasok ready mix }\end{array}$ \\
C6 & Manipulasi informasi oleh pemasok ready mix \\
C7 & Negosiasi tidak berjalan lancar oleh pihak pemasok ready mix \\
C8 & Tidak adanya petunjuk penggunaan peralatan dan material oleh \\
pemasok ready mix kepada kontraktor & Kurang baiknya proses pengawasan dokumen pengadaan \\
C10 & $\begin{array}{l}\text { Minimnya frekuensi diadakannya rapat koordinasi antara pihak- } \\
\text { pihak yang terlibat dalam proses konstruksi }\end{array}$ \\
\hline \hline
\end{tabular}

Variabel risiko rantai pasok pada hubungan kerja pemasok beton ready mix memiliki variabel yang sama dengan Tabel 2, tetapi dengan sudut pandang obyek berbeda yaitu persepsi pemasok terhadap kontraktor yang diberi kode variabel $D$, variabel $\mathrm{E}$, variabel $\mathrm{F}$.

\section{E. Responden Penelitian}

Respoden penelitian proyek Batiqa Hotel Surabaya dari pihak kontraktor yaitu :

1. Pimpinan Pelaksana Proyek

2. Site Manager

3. Staff Logistik

4. Staff Pengadaan barang

5. Quality Control

6. Quantity Surveyor

Responden penelitian dari pihak pemasok beton ready mix yaitu :

1. Kepala Batching Plant

2. Quality Control

3. Batcher

\section{F. Instrumen Penelitian}

Dalam penelitian ini, instrumen penilaian yang digunakan untuk mengukur probabilitas dan dampak adalah kuisioner. Skala yang digunakan untuk mengukur tingkat penilaian responden para pelaku yang terlibat dalam proyek Hotel Batiqa berupa metode scoring data yang berupa skala ordinal, menyangkut skala 1 sampai dengan 5 yang mereprentasikan probabilitas dan dampak yang terjadi di lapangan dengan penjelasan yaitu:

$$
\begin{aligned}
& \text { a. Angka } 1=\text { sangat rendah } / \text { kecil } \\
& \text { b. Angka } 2=\text { rendah } / \text { kecil } \\
& \text { c. Angka } 3=\text { cukup } \\
& \text { d. Angka } 4=\text { tinggi } / \text { besar } \\
& \text { e. Angka } 5=\text { sangat tinggi } / \text { besar }
\end{aligned}
$$

Kuisioner dilakukan dengan dua tahap yaitu survei pendahuluan yang bertujuan untuk mendapatkan variabel risiko yang relevan dengan variabel risiko yang telah disusun oleh penulis dari studi literatur. Berikutnya adalah survei utama yang bertujuan mendapatkan data yaitu berupa penilaian persepsi terhadap variabel risiko yang telah divalidasi oleh responden di tahap survei pendahuluan

b. Wawancara

Wawancara dilakukan dalam tujuan untuk mengetahui respon dan penanganan dari risiko yang berkategori tinggi dalam aktivitas rantai pasok pada proyek Hotel Batiqa Surabaya.

\section{H. Teknik Analisis Data}

Berikut adalah teknik analisis data dari penelitian ini :

1. Melakukan perhitungan probabilitas terjadinya peristiwa risiko dan dampak dari peristiwa risiko dengan menghitung nilai masing-masing kategori dari penilaian persepsi risiko yang telah diisi oleh para responden. Perhitungan nilai dapat menggunakan metode analisis Frequency Index \& Severity Index.

2. Memetakan hasil nilai setiap variabel risiko dari skala penilaian Frequency Index \& Severity Index untuk dapat menggolongkan suatu kejadian risiko ke dalam kategori rendah (zona hijau), sedang (zona kuning), atau tinggi (zona merah) dengan Matriks Probabilitas dan Dampak ${ }^{[8]}$, seperti anjuran dari PMOBK $5^{\text {th }}$ Edition. Contoh Matriks Probabilitas dan Dampak yang dimaksud dapat dilihat pada Gambar 3.

3. Setelah mendapatkan apa saja variabel risiko berkategori tinggi (zona merah), lalu peneliti melakukan survei respon risiko untuk mendapatkan informasi mengenai respon dari risiko berkategori tinggi tersebut dan pihak manakah yang menanggug risiko tersebut.

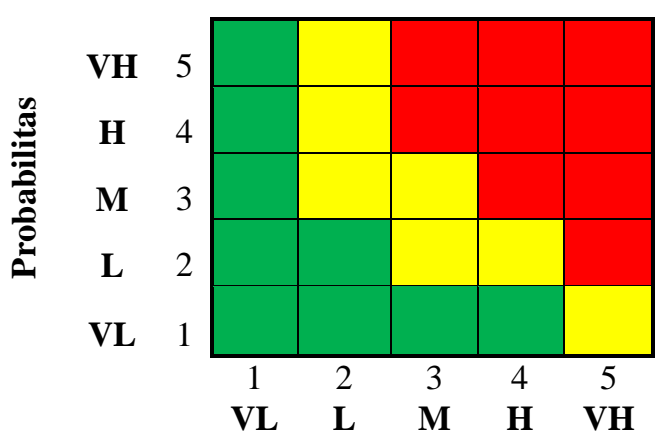

Keterangan :

\section{Dampak}

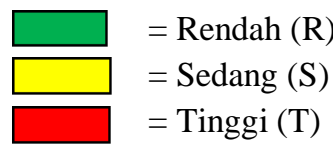

Gambar 3. Matriks Probabilitas dan Dampak

\section{G. Teknik Pengumpulan Data}

a. Kuisioner 


\section{PEMBAHASAN DAN ANALISIS DATA}

\section{A. Hasil Survei Pendahuluan}

Dari hasil survei pendahuluan, semua variabel risiko yang didapatkan oleh penulis dari literatur seluruhnya relevan dengan yang ada di lapangan

\section{B. Hasil Survei Utama}

Contoh hasil kuisioner probabilitas dan dampak untuk variable risiko B6 dapat dilihat pada Tabel 3 :

Tabel 3

Persepsi nilai Probabilitas dan Dampak Risiko Akibat Eskalasi Kenaikan Harga Material

\begin{tabular}{|c|c|c|c|c|c|c|c|c|c|c|c|}
\hline \multirow{3}{*}{ No } & \multirow{3}{*}{ Variabel Risiko } & \multirow{2}{*}{\multicolumn{5}{|c|}{$\begin{array}{c}\text { Probabilitas Risiko } \\
\text { Skala Penilaian }\end{array}$}} & \multirow{2}{*}{\multicolumn{5}{|c|}{$\begin{array}{l}\text { Dampak Risiko } \\
\text { Skala Penilaian }\end{array}$}} \\
\hline & & & & & & & & & & & \\
\hline & & 1 & 2 & 3 & 4 & 5 & 1 & 2 & 3 & 4 & 5 \\
\hline B6 & $\begin{array}{l}\text { Risiko akibat } \\
\text { eskalasi kenaikan } \\
\text { harga material }\end{array}$ & & 2 & 1 & 1 & & & 2 & & & 2 \\
\hline
\end{tabular}

Berdasarkan Tabel 3 tersebut, kemudian dilakukan perhitungan Frequency Index dan Severity Index sebagai berikut:

- $F I=\frac{\sum_{i=0}^{4} a_{i} x_{i}}{4 \sum_{i=0}^{4} x_{i}} \times 100 \%$

Maka,

$$
\begin{gathered}
F I=\frac{a_{0} x_{0}+a_{1} x_{1}+a_{2} x_{2}+a_{3} x_{3}+a_{4} x_{4}}{4\left(x_{0}+x_{1}+x_{2}+x_{3}+x_{4}\right)} \times 100 \% \\
F I=\frac{0 x 0+1 \times 2+2 x 1+3 x 1+4 x 0}{4(0+2+1+1+0)} \times 100 \% \\
\boldsymbol{F I}=\mathbf{4 3}, \mathbf{7 5} \%
\end{gathered}
$$

- $S I=\frac{\sum_{i=0}^{4} a_{i} x_{i}}{4 \sum_{i=0}^{4} x_{i}} \times 100 \%$

Maka,

$$
\begin{gathered}
S I=\frac{a_{0} x_{0}+a_{1} x_{1}+a_{2} x_{2}+a_{3} x_{3}+a_{4} x_{4}}{4\left(x_{0}+x_{1}+x_{2}+x_{3}+x_{4}\right)} \times 100 \% \\
S I=\frac{0 x 0+1 x 2+2 x 0+3 x 0+4 x 2}{4(0+2+0+0+2)} \times 100 \% \\
\text { SI }=\mathbf{6 3}, \mathbf{5} \%
\end{gathered}
$$

Nilai FI dan SI tersebut kemudian diklasifikasikan dengan aturan sebagai berikut :

$0 \%<\mathrm{FI} \leq 20 \%=$ Sangat Rendah $/$ Very Low

$20 \%<\mathrm{FI} \leq 40 \%=$ Rendah $/$ Low

$40 \%<\mathrm{FI} \leq 60 \%=$ Cukup $/$ Moderate

$60 \%<\mathrm{FI} \leq 80 \%=$ Tinggi $/$ High

$80 \%<\mathrm{FI} \leq 100 \%=$ Sangat Tinggi $/$ Very High

Setelah itu setiap kategori diberi penilaian sebagai berikut :

Sangat Rendah / Very Low $=1$

Rendah / Low $\quad=2$

Cukup / Moderate $\quad=3$

Tinggi / High $\quad=4$

Sangat Tinggi / Very High $=5$
Maka, nilai Frequency Index dan Severity Index dari variabel B6 bernilai 3 dan 4. Setelah mendapatkan nilai FI dan SI dari masing-masing variabel, langkah selanjutnya yaitu melakukan pemetaan nilai tersebut pada Matriks Probabilitas dan Dampak.

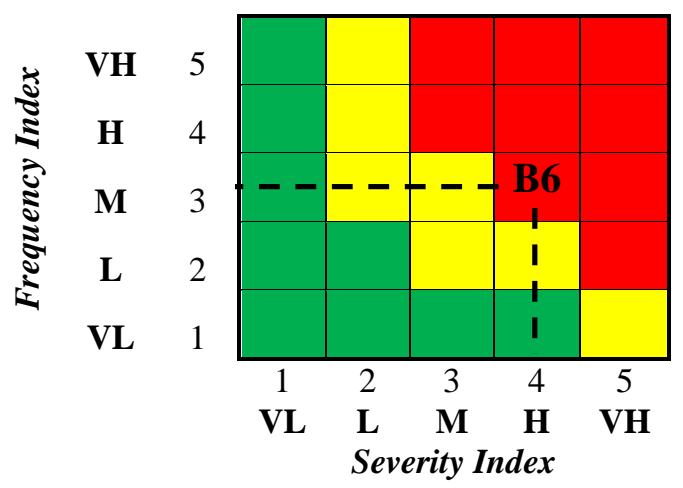

Gambar 4. Matriks Probabilitas dan Dampak Variabel B6

Hasil dari seluruh survei utama adalah sebagai berikut :

a. Analisis persepsi risiko kontraktor terhadap pemasok ready mix

Hasil Matriks Probabilitas dan Dampak risiko kontraktor terhadap pemasok beton ready mix dapat dilihat di Gambar 5 :

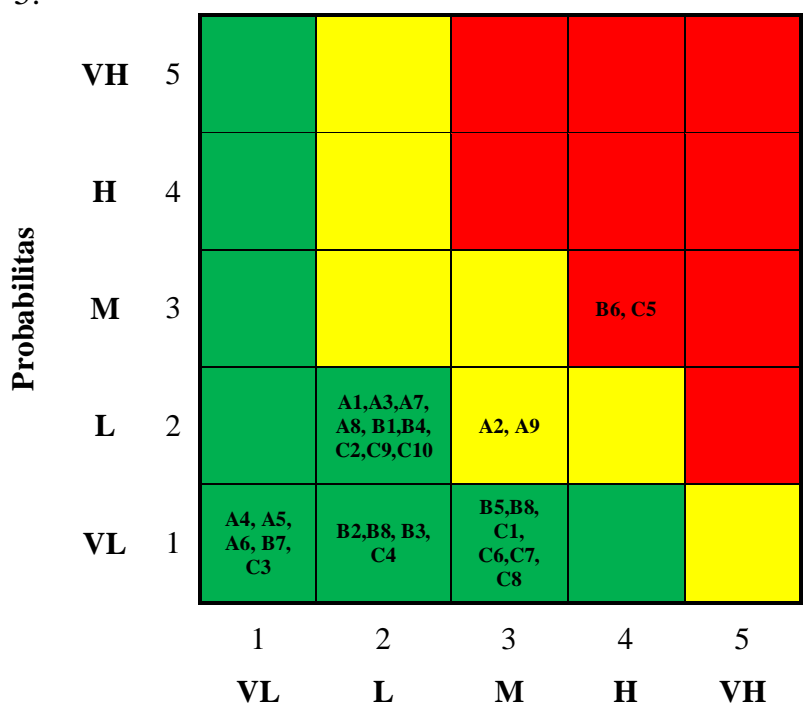

Dampak

Gambar 5. Matriks Probabilitas dan Dampak Risiko Kontraktor terhadap Pemasok Ready Mix

Variabel dengan kategori risiko tinggi pada hubungan rantai pasok kontraktor terhadap pemasok beton raedy mix :

1. Risiko akibat eskalasi kenaikan harga material.

2. Risiko adanya pengajuan klaim dari pihak kontraktor atas ketidakpuasan material yang telah dikirim oleh pemasok ready mix.

b. Analisis persepsi risiko pemasok ready mix terhadap kontraktor.

Hasil Matriks Probabilitas dan Dampak risiko kontraktor terhadap pemasok beton ready mix dapat dilihat di Gambar 6: 


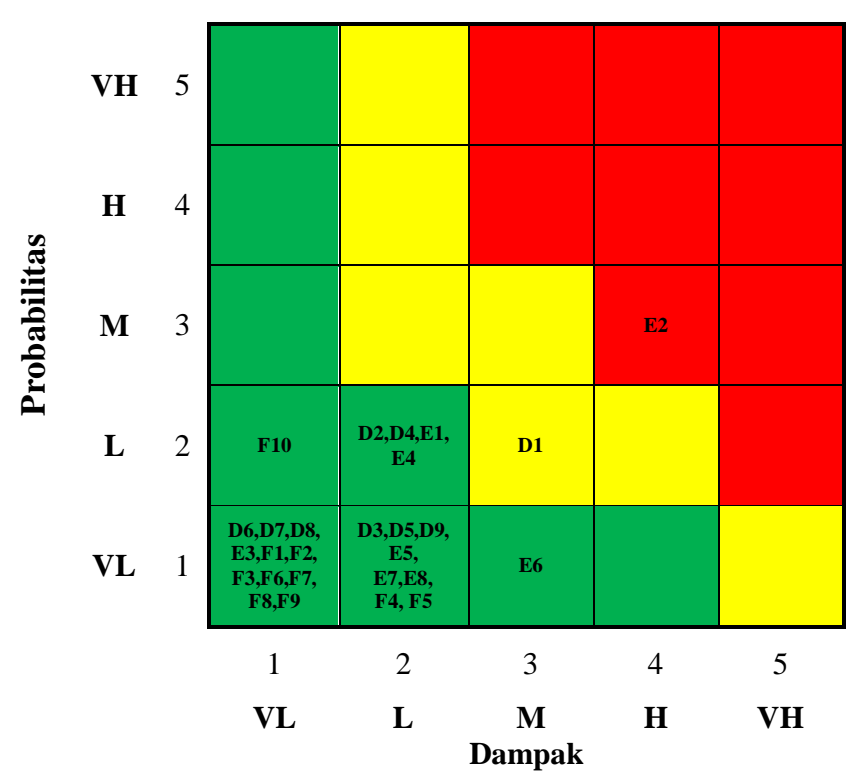

Gambar 6. Matriks Probabilitas dan Dampak Risiko Pemasok Ready Mix Terhadap Kontraktor.

Variabel dengan kategori risiko tinggi pada hubungan rantai pasok pemasok beton raedy mix terhadap kontraktor adalah risiko harga yang diberikan oleh pemasok ready mix kepada pihak kontraktor kurang kompetitif

\section{Hasil Survei Respon Risiko}

Untuk penelitian ini, survei respon risiko hanya dilakukan pada variabel risiko yang berkategori tinggi saja. Respon risiko sendiri pada umumnya tidak hanya langkah untuk menangani risiko yang sudah terjadi (respon risiko kuratif), tetapi lebih baik apabila pelaku proyek berupaya agar risiko tersebut dapat dihindari (respon risiko preventif).

a. Respon Risiko Kontraktor terhadap Pemasok

Tabel 3

Hasil Survei Respon Risiko Kontraktor terhadap Pemasok

\begin{tabular}{|c|c|}
\hline Variabel Risiko: & $\begin{array}{l}\text { Kenaikan Harga Material } \\
\text { 1. Perubahan desain dari spesifikasi beton } \\
\text { yang sudah dipesan }\end{array}$ \\
\hline Faktor Penyebab & $\begin{array}{l}\text { 2. Adanya kemunduran jadwal proyek, } \\
\text { sehingga ada klaim kenaikan harga dari } \\
\text { pihak pemasok }\end{array}$ \\
\hline Dampak & $\begin{array}{l}\text { Biaya dari proyek membengkak karena } \\
\text { kenaikan harga material beton ready mix } \\
\text { 1. Memastikan desain yang benar agar tidak } \\
\text { terjadi perubahan setelah pemesanan }\end{array}$ \\
\hline Strategi Risiko Preventif & $\begin{array}{l}\text { 2. Membuat perjanjian kontrak jangka } \\
\text { panjang dengan pemasok, sehingga } \\
\text { kontraktor dapat menghindari kenaikan } \\
\text { harga }\end{array}$ \\
\hline Strategi Risiko Kuratif & $\begin{array}{l}\text { Mencari opsi pemasok beton yang dapat } \\
\text { memenuhi harga yang diinginkan } \\
\text { kontraktor }\end{array}$ \\
\hline Variabel Risiko : & $\begin{array}{l}\text { Pengajuan klaim dari pihak kontraktor atas } \\
\text { ketidakpuasan material yang telah dikirim } \\
\text { oleh pemasok beton ready mix }\end{array}$ \\
\hline Faktor Penyebab & $\begin{array}{l}\text { Mutu dari hasil produksi beton pemasok } \\
\text { tidak sesuai dengan spesifikasi yang } \\
\text { dikehendaki kontraktor }\end{array}$ \\
\hline Dampak & $\begin{array}{l}\text { Ada kemunduran jadwal, sehingga } \\
\text { menyebabkan biaya membengkak }\end{array}$ \\
\hline
\end{tabular}

Kenaikan Harga Material

yang sudah dipesan

2. Adanya kemunduran jadwal proyek pihak pemasok

kenaikan harga material beton ready mix terjadi perubahan setelah pemesanan

2. Membuat perjanjian kontrak jang kontraktor dapat menghindari kenaikan memenuhi harga yang diinginkan kontraktor oleh pemasok beton ready mix Mutu dari hasil produksi beton pemasok dikehendaki kontraktor menyebabkan biaya membengkak
Strategi Risiko Preventif

1. Melakukan survei untuk mendapatka referensi pemasok ready mix yang berkualitas

2. Melakukan pengecekan mutu oleh kontraktor sebelum pengecoran Meminta pertanggungjawaban pemasok

Strategi Risiko Kuratif untuk mengganti ready mix sesuai dengan spesifikasi

\section{b. Respon Risiko Supplier terhadap Kontraktor}

Tabel 4

Hasil Survei Respon Risiko Pemasok terhadap Kontraktor

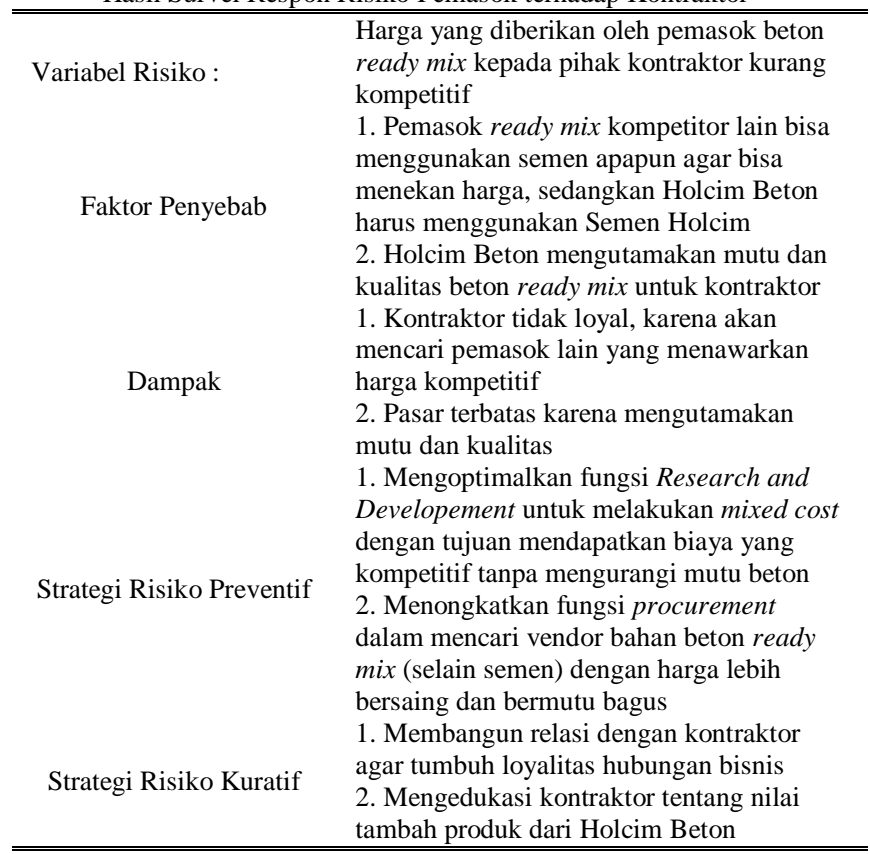

\section{KESIMPULAN}

Berdasarkan keseluruhan hasil analisis risiko rantai pasok beton ready mix pada proyek Hotel Batiqa dapat ditarik beberapa kesimpulan, diantaranya sebagai berikut :

1. Dari hasil analisis data dari persepsi probabilitas dampak dan risiko, berikut adalah variabel risiko berkategori tinggi yang terjadi pada aktivitas rantai pasok :

a. Persepsi Kontraktor terhadap Pemasok

- Risiko terjadinya eskalasi kenaikan harga material

- Risiko adanya pengajuan klaim dari pihak kontraktor atas ketidakpuasan material yang telah dikirim oleh pemasok beton ready mix

b. Persepsi Pemasok terhadap Kontraktor

- Risiko harga yang diberikan oleh pemasok ready mix kepada pihak kontraktor kurang kompetitif.

2. Respon Risiko

Dari hasil survei respon risiko yang dilakukan dengan wawancara terhadap pelaku aktivitas rantai pasok beton ready mix, maka hasilnya sebagai berikut :

a. Persepsi Kontraktor terhadap Pemasok

Untuk risiko kenaikan harga material dari pemasok ready mix, kontraktor akan melakukan tindakan preventif yaitu membuat kontrak jangka panjang dengan pemasok ready mix agar kontraktor dapat menghindari kenaikan harga material. Sedangkan untuk risiko apabila kontraktor tidak 
puas dengan material yang dikirimkan oleh pemasok ready mix, maka kontraktor sebelumnya sudah mempunyai referensi pemasok ready mix yang berkualitas.

b. Persepsi Pemasok terhadap Kontraktor

Untuk risiko terkait dengan harga yang diberikan pemasok ready mix yang kurang kompetitif, pemasok akan mengoptiumalkan fungsi Research and Developement untuk melakukan mixed cost serta mencari vendor bahan beton ready mix (selain semen) yang lebih bersaing harganya sehingga pemasok ready mix dapat menekan harga jual kepada kontraktor.

\section{DAFTAR PUSTAKA}

[1] Indrajit, R.E. \& Djokopranoto, R. 2002. Konsep Manajemen Supply Chain. Jakarta: Grasindo.

[2] Project Management Institute. 1992. Project and Program Risk Management, A Guide to Managing Risk and Opportunities. The PMBOK Handbook Series Volume no 6. United State of America.

[3] Nurcahyo, Cahyono Bintang \& Wiguna, I. Putu Artama. Agustus 2016. "Analisis Risiko Rantai Pasok Beton Ready Mix pada Proyek Pembangunan Apartemen di Surabaya". Jurnal Aplikasi Teknik Sipil Volume 14, No. 2.

[4] Baskoro, B. 2013. "Analisis Risiko pada Proyek Fly-Over Pasar Kembang Surabaya”. Penelitian Program Studi Sarjana. Surabaya: Institut Teknologi Sepuluh Nopember.

[5] Belliawan, A. 2011. "Analisis Risiko Konstruksi pada Proyek Trillium Office and Residence". Penelitian Program Studi Sarjana. Surabaya: Institut Teknologi Sepuluh Nopember.

[6] Soetowijoyo, H. 2011. "Penilaian Persepsi Risiko Rantai Pasok pada Proyek Konstruksi Gedung Surabaya". Tesis Program Studi Pasca Sarjana. Surabaya: Institut Teknologi Sepuluh Nopember.

[7] Soepiadhy, S. 2011. "Pengaruh Rantai Pasok Terhadap Kontraktor Bangunan Gedung di Jember". Tesis Program Studi Pasca Sarjana. Surabaya: Institut Teknologi Sepuluh Nopember.

[8] Project Management Institute. 2013. A User's Manual to the PMBOK Guide ( $5^{\text {th }}$ Edition). United State of America. 